\title{
Molecular structure of mono- and 1,2-aminoderivatives of cyclohexane: Steric strain effects as determining factors
}

\author{
Luciana I.N. Tomé, Mário T.S. Rosado *, M. Ermelinda S.Eusébio, J.S. Redinha \\ Department of Chemistry, University of Coimbra, 3004-535 Coimbra, Portugal
}

Received 20 July 2006; accepted 28 September 2006

Available online 14 October 2006

\begin{abstract}
The conformational study of cyclohexylamine and 1,2-cyclohexylamine derivatives was performed. The potential energy surface of every compound was calculated at B3LYP/6-31G(d) and the conformational energy minima were further optimized at B3LYP/augcc-pVDZ level of theory. The geometrical parameters and the electronic energy of each conformer were determined. The internal energy, enthalpy, entropy, Gibbs energy and the relative weight of each conformer in the structure of the respective isomer were calculated at $298.15 \mathrm{~K}$. The steric hindrances in the crowded molecules resulting from the replacement of hydrogens of cyclohexane by amine groups are pointed out by short non-bonded $\mathrm{H} \leftrightarrow \mathrm{H}$ distances and by the consequent bond and dihedral angles distortions relatively to the cyclohexane structure.
\end{abstract}

(C) 2006 Elsevier B.V. All rights reserved.

Keywords: Amines; Cyclohexane; Steric effects; H-bond; DFT; Strain; Thermodynamics

\section{Introduction}

Cyclohexane derivatives have become, for a long time past, [1] the center of attention of a large number of authors [2-4] because, either alone or as part of more complex units, are ubiquous in nature [5] and find numerous applications in chemical and pharmaceutical industries [6]. Moreover, from this type of compounds valuable information on the structural point of view can be taken. Indeed, these compounds are suitable to model important structural features determinant to the electronic energy, involving the occurrence of simultaneous interactions between molecular groups, namely hydrogen bonding and steric effects.

Despite the work carried out on mono, [7-14] di [12,1518] and polysubstituted [19] cyclohexanes and the importance of the aminoderivatives, publications on the latter are quite scarce. It is rather surprising because first, the amine group is present in a variety of molecules, making part of a large number of compounds of biological interest;

\footnotetext{
* Corresponding author.

E-mail address: mtulio@qui.uc.pt (M.T.S. Rosado).
}

second, the amines are used in the production of numerous chemicals and as auxiliary molecules in organic synthesis. As significant examples: cyclohexylamine is used in the production of pharmaceuticals and other chemicals including insecticides, pesticides, plasticizers, emulsifying agents, dyes, dry cleaning agents and corrosion inhibitors [6]; trans-cyclohexyl-1,2-diamine is commonly used in the preparation of ligands in the growing field of asymmetric synthesis and chiral molecular recognition [20-24].

In this study, the energies of the most stable conformers of cyclohexylamine, cis-cyclohexyl-1,2-diamine and trans-cyclohexyl-1,2-diamine were determined by density functional theory calculations (DFT). From the values found for the electronic energy and for the relative populations of the conformers, the mean Gibbs energy, enthalpy and entropy of the isomers in the gas state at $298.15 \mathrm{~K}$ were obtained.

\section{Computational methods}

The energy difference between chair and boat cyclohexane ring conformations is high enough [25-28] to consider, for cyclohexane derivatives, only the chair structure [7-18]. 
The chair structure has two possible equivalent conformations. When the ring flips back and forth, the bonds that are axial become equatorial and vice-versa. In a 1,2-disubstituted cyclohexane, the trans isomer has both substituents either axial or equatorial, while in the cis, one is axial and the other is equatorial. The conformational studies performed here were thus carried out for every possible chair conformation of cyclohexylamine; cis-cyclohexyl-1,2-diamine and trans-cyclohexyl-1,2-diamine.

From the conformational point of view, cyclohexylamines are relatively simple molecules and their flexibility only derives from the rotation around the $\mathrm{C}-\mathrm{N}$ bonds, which can be described by the $\mathrm{Lp}-\mathrm{N}-\mathrm{C}-\mathrm{H}$ dihedrals ( $\mathrm{Lp}$ is the idealized plane of the nitrogen lone electron pair). These internal coordinates were scanned to derive all relevant conformations.

The potential energy scan for the monoamine was obtained by restricting the dihedral $\mathrm{Lp}-\mathrm{N}-\mathrm{C}-\mathrm{H}$ in $10^{\circ}$ steps. As far as the potential energy scan for the diamines is concerned, the two $\mathrm{Lp}-\mathrm{N}-\mathrm{C}-\mathrm{H}$ dihedrals were fixed at $20^{\circ}$ step values, resulting in a 324 points three dimensional grid corresponding to the potential energy surface of the molecule. All other internal coordinates in these structures were optimized by DFT calculations [29,30] using the B3LYP functional [31-33] and the 6-31G(d) basis set. These initial scans with a low cost basis set shortened the computational effort, providing the starting structures for the higher level calculations.

Next, the structure of all local minima inferred by the shape of the potential energy surface of each amine was further optimized at a higher level of theory, employing the standard polarized (p) and correlation-consistent (cc) double-zeta basis set by Dunning augmented by diffuse functions (aug-cc-pVDZ), [34,35] followed by vibrational frequencies calculation to elucidate the nature of each resulting stationary point.

All the DFT calculations were performed using the Gaussian98 program package [36], running in a PC.

The minimized electronic energy $\left(E_{\text {elec }}\right)$ provided by the geometry optimization was corrected with the zero-point vibrational energy $\left(E_{\mathrm{ZPE}}\right)$ and thermal corrections ( $\left.E_{\text {trans }}+E_{\text {rot }}+E_{\mathrm{vib}}\right)$ obtained according to the standard statistical thermodynamic methods based on the ideal gas - rigid rotor - harmonic oscillator model. Thus, the enthalpy $(H)$ of each conformer at $298.15 \mathrm{~K}$ was then determined using the expression [37]:

$H=E_{\text {elec }}+E_{\mathrm{ZPE}}+E_{\text {trans }}+E_{\text {rot }}+E_{\text {vib }}+R T$

The entropy $(S)$ was calculated by the same methods, [37] corrected by the degeneracy degree of each conformer and used to obtain the values of the Gibbs energy $(G)$, using the equation

$G=H-T S$

The values taken for the enthalpy, entropy and Gibbs energy of the molecule in the gas state are the weighted mean values found for the thermodynamic functions, calculated as follows:

$Z_{\mathrm{gas}}=\sum_{i} Z(i) P(i)$

$Z$ stands for the thermodynamic function and $P($ i) for the equilibrium population of each conformer. The equilibrium population was calculated according to the Boltzmann distribution, based on the Gibbs energy at $298.15 \mathrm{~K}$.

\section{Results and discussion}

\subsection{Cyclohexylamine}

Cyclohexylamine is the natural starting point for the study of any amine-substituted cyclohexane. In this simpler molecule, one can isolate the conformational effects on the cyclohexane structure due to the presence of the simplest aminic group from those arising from the substituent complexity or from the presence of other substituents.

Two cyclohexylamine isomers were considered, one with the $\mathrm{NH}_{2}$ group equatorial and the other with this group axially oriented relatively to the ring. The potential energy surfaces of both forms calculated at B3LYP/6-31G(d) level of theory are depicted in Fig. 1. The energy curve pattern is identical for both cyclohexylamines, exhibiting three energy minima, one for the trans conformation ( $\mathrm{Lp}-\mathrm{N}-\mathrm{C}-$ $\mathrm{H}=180^{\circ}$ ) and two symmetric degenerate ones for the gauche ( $\mathrm{Lp}-\mathrm{N}-\mathrm{C}-\mathrm{H}= \pm 60^{\circ}$ ). However, while in the equatorial cyclohexylamine no significant energy difference is observed between the three energy minima, in the axial isomer the energy of the trans conformation is lower than that of the gauche conformations by approximately $2 \mathrm{~kJ} \mathrm{~mol}^{-1}$. The potential energy surfaces show further that the equatorial form is more stable than the axial one. The energy difference between both isomers is $4 \mathrm{~kJ} \mathrm{~mol}^{-1}$ for the trans conformers and $7 \mathrm{~kJ} \mathrm{~mol}^{-1}$ for the gauche conformers.

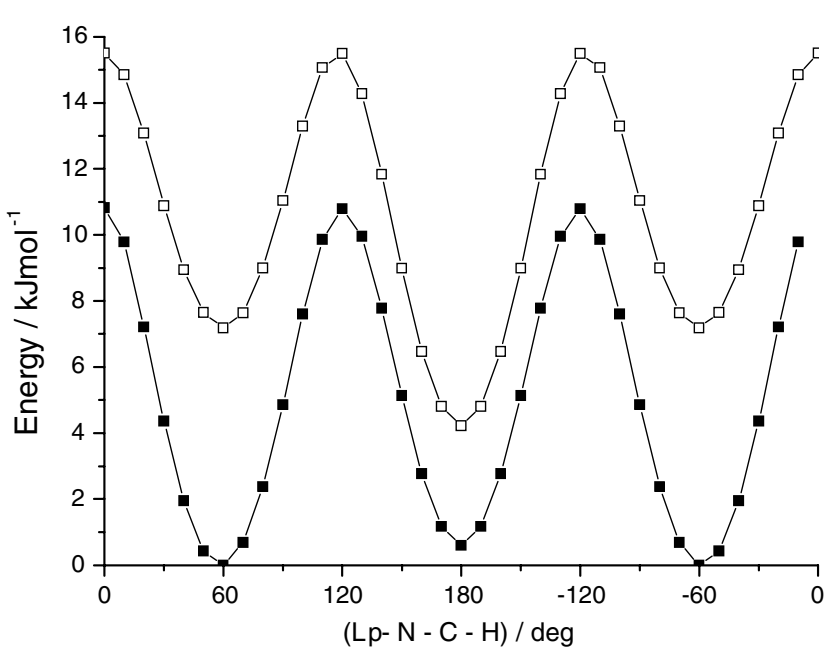

Fig. 1. B3LYP/6-31G(d) potential energy curves for equatorial (घ) and axial $(\square)$ cyclohexylamine. 
Thus, two dominant equatorial conformers and two less important axial ones are expected in the structure of cyclohexylamine. The four non-degenerated structures corresponding to the six local minima of the potential energy surface were, as mentioned above, completely optimized at the B3LYP/aug-cc-pVDZ level of theory.

The relevant dihedral angle value, the electronic energy and the contribution of each conformer to thermodynamic quantities at $298.15 \mathrm{~K}$ - internal energy, enthalpy, entropy term and Gibbs energy - are presented in Table 1. The equilibrium population of the conformers, calculated from the Gibbs energy at $298.15 \mathrm{~K}$, is also included in this table. The conformers are numbered following the increasing order of their electronic energy and their structures are displayed in Fig. 2. The electronic energy expressed in kJ $\mathrm{mol}^{-1}$ is given inside parenthesis next to the structure. Throughout this article, subscripts e and a are used to assist in the identification of equatorial and axial atoms connecting to the cyclohexane ring. Complete geometry data for the conformers is available on-line as supplementary information.
As expected from the potential energy surface, the equatorial aminoderivatives are more stable than the axial ones. The electronic energy of the most stable axial conformer is $4.88 \mathrm{~kJ} \mathrm{~mol}^{-1}$ above that of the less stable equatorial conformer. Another structural feature evidenced by the potential energy surfaces and confirmed by the higher level theory calculation is the small difference between the energy of the trans and gauche structures in equatorial cyclohexylamine and the accentuated difference between the conformers of the axial isomer.

The relative population of the conformers given by the Gibbs energy differ significantly from those based on the electronic energy or enthalpy. Indeed, an order inversion of $\mathrm{cI}$ and cII and a smaller difference of the $G_{\mathrm{i}}$ values between cIII and cIV are observed due to the effect of the entropy. The values of the relative entropies and their vibrational, rotational and degeneracy components are given in Table 2. The increase of entropy from cI to cII, ascribed fundamentally to the degeneracy difference, is high enough to overweight the enthalpy difference between both conformers, so that cII becomes the prevailing structure of

Table 1

Characteristic dihedral and relative electronic energies $\left(E_{\mathrm{elec}, \mathrm{i}}\right)$, as well as internal energies $\left(E_{\mathrm{i}}\right)$, enthalpies $\left(H_{\mathrm{i}}\right)$, entropy terms $\left(\mathrm{T} S_{\mathrm{i}}\right)$, Gibbs energy $\left(G_{\mathrm{i}}\right)$ and equilibrium populations $\left(P_{\mathrm{i}}\right)$ at $298.15 \mathrm{~K}$ for the B3LYP/aug-cc-pVDZ optimized structures of the conformers of cyclohexylamine

\begin{tabular}{|c|c|c|c|c|c|c|c|}
\hline Conformer & $(\mathrm{Lp}-\mathrm{N}-\mathrm{C}-\mathrm{H}) / \mathrm{deg}$ & $E_{\text {elec }, \mathrm{i}} /$ Hartree & $E_{\mathrm{i}} /$ Hartree & $H_{\mathrm{i}} /$ Hartree & $\mathrm{T} S_{\mathrm{i}} /$ Hartree & $G_{\mathrm{i}} /$ Hartree & $P_{\mathrm{i}}(\%)^{\mathrm{a}}$ \\
\hline cI & 180.00 & -291.2632614 & -291.0700264 & -291.0690814 & 0.038436 & -291.1075174 & $35.7(1)$ \\
\hline cII & -59.15 & -291.2629602 & -291.0697612 & -291.0688172 & 0.039178 & -291.1079956 & $59.3(2)$ \\
\hline cIII & 180.00 & -291.2611014 & -291.0677724 & -291.0668284 & 0.038381 & -291.1052094 & $3.1(1)$ \\
\hline cIV & -60.56 & -291.2599565 & -291.0665575 & -291.0656135 & 0.039113 & -291.1047269 & $1.9(2)$ \\
\hline
\end{tabular}

${ }^{\text {a }}$ Numbers in parenthesis correspond to the degeneracy degree of conformers.
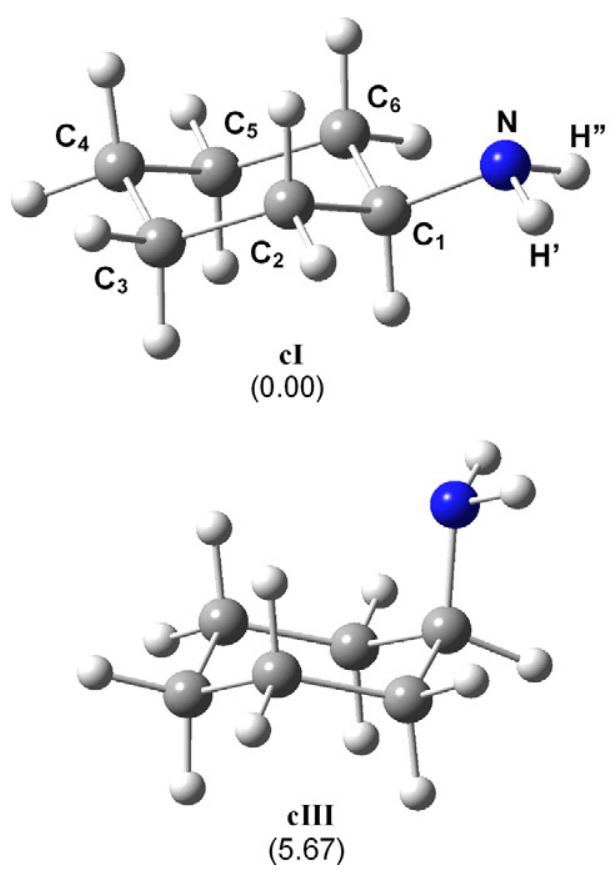

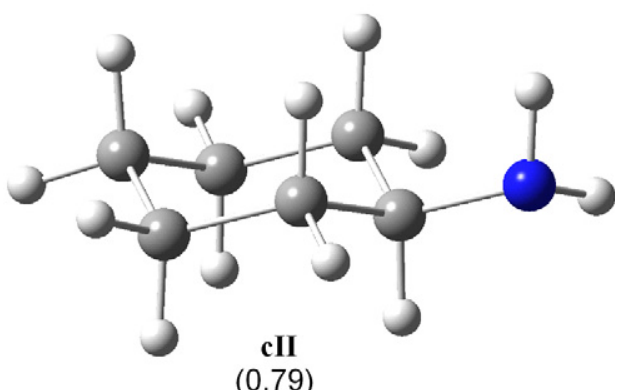

$(0.79)$

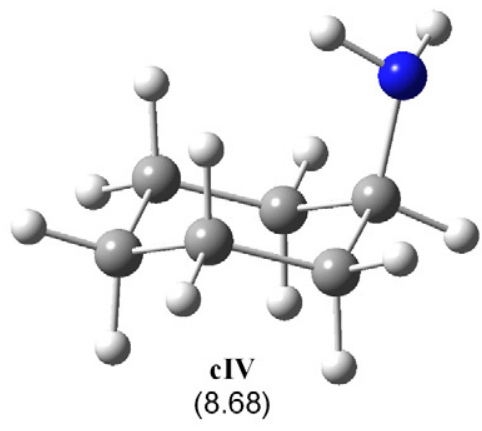

Fig. 2. B3LYP/aug-cc-pVDZ optimized geometries of the conformers of cyclohexylamine. The values inside parenthesis represent the energy, relatively to the most stable conformer in $\mathrm{kJ} \mathrm{mol}^{-1}$. 
Table 2

The relative values of vibrational, rotational and degeneracy components in the entropy of cyclohexylamine and the sum of these contributions, in $\mathrm{Jmol}^{-1} \mathrm{~K}^{-1}$

\begin{tabular}{llrrr}
\hline Conformer & $S_{\text {vib }}$ & \multicolumn{1}{c}{$S_{\text {rot }}$} & $S_{\text {deg }}$ & $S_{\text {total }}$ \\
\hline cI & 0.00 & 0.00 & 0.00 & 0.00 \\
cII & 0.73 & 0.05 & 5.76 & 6.54 \\
cIII & 0.20 & -0.69 & 0.00 & -0.48 \\
cIV & 0.82 & -0.61 & 5.76 & 5.97 \\
\hline
\end{tabular}

at room temperature. An opposite effect of the entropic term on the Gibbs energy occurs in cIII. Its relative weight in the conformational space of cyclohexylamine expected from the enthalpy is decreased by its lower rotational entropy.

The axial cyclohexylamine can be considered as resulting from the equatorial conformer by ring flip. The thermodynamic quantities necessary to convert one chair conformation in to the other at $298.15 \mathrm{~K}$ are: $\Delta H=6.35 \mathrm{~kJ}$ $\mathrm{mol}^{-1}, \Delta S=-2.14 \mathrm{~J} \mathrm{~mol}^{-1} \mathrm{~K}^{-1}$ and $\Delta G^{\circ}=7.28 \mathrm{~kJ} \mathrm{~mol}^{-1}$. The corresponding equilibrium constant is $K=5.3 \times 10^{-2}$. To our knowledge, only one work was published on the aminocyclohexane conformation [38]. Using ${ }^{15} \mathrm{~N}$ NMR the authors obtained the values $(1.44 \pm 0.07) \mathrm{kcalmol}^{-1} \quad$ in $\quad \mathrm{C}_{7} \mathrm{D}_{8} \quad$ and $(1.41 \pm 0.07) \mathrm{kcalmol}^{-1}$ in $\mathrm{CD}_{2} \mathrm{Cl}_{2}$ for $\Delta G$ of the conversion of the equatorial into axial aminocyclohexane at $173 \mathrm{~K}$. These results cannot be compared with those calculated in this paper attending to the different temperatures at which they were obtained.

An approach to interpret the conformer structures in molecular terms is now brought forward. The chair cyclohexane conformation is commonly considered a strainless structure. When a hydrogen atom is replaced by a higher size atom or group, repulsive interactions between nonbonded atoms arise in order to get room to accommodate the substituent. The steric repulsion involving the hydrogen atoms of the amine group imposes serious constraints on the geometry of the cyclohexane ring increasing strain. Thus, two types of features are strain connoted, one is the steric repulsion between non-bonded hydrogen atoms in the crowded derivative molecule, and the other, interrelated with the former, is the cyclohexane ring deformation.
The conformers correspond to orientations of the amine group that minimize the strain energy as much as possible.

It is quite understandable that cyclohexane would be the most suitable reference in the study of its derivatives, since it can be considered a strain free molecule as stated above. The geometry optimization of cyclohexane was then performed at the same level of theory employed in the study of the derivatives. Fairly short $\mathrm{H} \leftrightarrow \mathrm{H}$ distances and the variations of bond angles relatively to the cyclohexane are taken as strain manifestations in the derivative.

In Table 3 are given the differences found for the molecular parameters altered by the substitution of the hydrogen atom by the amino group. For space reasons only the main variations are quoted. Taking into account the distances between non-bonded hydrogen atoms in cyclohexane $\left(\mathrm{H}_{\mathrm{e}} \leftrightarrow \mathrm{H}_{\mathrm{e} \alpha}=2.517 \AA ; \quad \mathrm{H}_{\mathrm{a}} \leftrightarrow \mathrm{H}_{\mathrm{a} \beta}=2.659 \AA ; \quad \mathrm{H}_{\mathrm{a}} \leftrightarrow \mathrm{H}_{\mathrm{e}}\right.$ (substituents of vicinal carbon atoms) $=2.482 \AA$ ) only values below the last one were considered as $\mathrm{H} \leftrightarrow H$ strain manifestations. This limit is coherent with $1.20 \AA$ tabled for the hydrogen van der Waals radius [39].

The structure of cI is essentially determined by the repulsive interaction between $\mathrm{H}_{1 \mathrm{a}}$ and both hydrogens of the amino group, giving rise to a displacement of $\mathrm{N}$ and $\mathrm{H}_{1 \mathrm{a}}$ inwards the ring. As the $\mathrm{NH}_{2}$ rotates and becomes $g$ or $g^{\prime}$ (cII), a strong repulsion between $\mathrm{H}_{\mathrm{Ne}}^{\prime}$ and $\mathrm{H}_{1 \mathrm{a}}$ or between $\mathrm{H}_{\mathrm{Ne}}^{\prime \prime}$ and $\mathrm{H}_{1 \mathrm{a}}$ takes place. The resulting structure differs from that of the former conformer by a higher increase of $\mathrm{N}_{\mathrm{e}}-\mathrm{C}_{1}-\mathrm{C}_{2}$ or $\mathrm{N}_{\mathrm{e}}-\mathrm{C}_{1}-\mathrm{C}_{6}$ angles.

The replacement of an axial hydrogen atom of cyclohexane by the amine group is accompanied by more pronounced structure variations than those observed in the equatorial isomer. The specific configuration of the $\mathrm{NH}_{2}$ group in cIII makes both hydrogen atoms of the substituent interact with $\mathrm{H}_{1 \mathrm{e}}, \mathrm{H}_{2 \mathrm{e}}$ and $\mathrm{H}_{6 \mathrm{e}}$. An appreciable distortion of the ring, consisting in the decrease of the angle between the $\mathrm{C}_{1}-\mathrm{H}_{1}$ bond and the $\mathrm{C}_{1} \mathrm{C}_{2} \mathrm{C}_{6}$ plane and of the angle formed by this bond with $\mathrm{C}_{1}-\mathrm{C}_{2}$ can be observed. In cIV, strong steric repulsions are observed between the hydrogens of the amino group and $\mathrm{H}_{3 \mathrm{a}}, \mathrm{H}_{5 \mathrm{a}}$ and $\mathrm{H}_{1 \mathrm{e}}$. The nitrogen atom is pushed inwards to the ring and simultaneously $\mathrm{H}_{1 \mathrm{e}}$ moves in the opposite direction so that the $\mathrm{N}_{\mathrm{a}} \mathrm{C}_{1} \mathrm{C}_{2}$ angle is strongly increased. In the other degenerated conformer the variation of $\mathrm{N}_{\mathrm{a}} \mathrm{C}_{1} \mathrm{C}_{2}$ is in the opposite direction.

Table 3

Variation of bond angles upon replacement of the hydrogen atom by the amine group in cyclohexane and non-bonded $\mathrm{H}-\mathrm{H}$ distances in cyclohexylamine

\begin{tabular}{|c|c|c|c|c|}
\hline \multirow{2}{*}{$\begin{array}{l}\text { Conformer } \\
\mathrm{cI}\end{array}$} & \multicolumn{2}{|c|}{ Non-bonded $\mathrm{H}-\mathrm{H}$ distances/Å } & \multicolumn{2}{|c|}{ Variation of bond and torsional angles/deg } \\
\hline & $\mathrm{H}_{\mathrm{Ne}}^{\prime} \leftrightarrow \mathrm{H}_{1 \mathrm{a}}=2.45$ & $\mathrm{H}_{\mathrm{Ne}}^{\prime \prime} \leftrightarrow \mathrm{H}_{1 \mathrm{a}}=2.45$ & $\begin{array}{l}\left(\mathrm{H}_{1 \mathrm{a}} \mathrm{C}_{1} \mathrm{C}_{3} \mathrm{C}_{5}\right)=-1.86 \\
\left(\mathrm{H}_{1 \mathrm{a}} \mathrm{C}_{1} \mathrm{C}_{2}\right)=-1.52\end{array}$ & $\left(\mathrm{~N}_{\mathrm{e}} \mathrm{C}_{1} \mathrm{C}_{2} \mathrm{C}_{6}\right)=-1.82$ \\
\hline cII & $\mathrm{H}_{\mathrm{Ne}}^{\prime} \leftrightarrow \mathrm{H}_{1 \mathrm{a}}=2.38$ & & $\begin{array}{l}\left(\mathrm{H}_{1 \mathrm{a}} \mathrm{C}_{1} \mathrm{C}_{3} \mathrm{C}_{5}\right)=-1.36 \\
\left(\mathrm{~N}_{\mathrm{e}} \mathrm{C}_{1} \mathrm{C}_{2}\right)=4.50\end{array}$ & $\begin{array}{l}\left(\mathrm{N}_{\mathrm{e}} \mathrm{C}_{1} \mathrm{C}_{2} \mathrm{C}_{6}\right)=-1.52 \\
\left(\mathrm{H}_{1 \mathrm{a}} \mathrm{C}_{1} \mathrm{C}_{2}\right)=-1.18\end{array}$ \\
\hline cIII & $\begin{array}{l}\mathrm{H}_{\mathrm{Na}}^{\prime \prime} \leftrightarrow \mathrm{H}_{2 \mathrm{e}}=2.44 \\
\mathrm{H}_{\mathrm{Na}}^{\prime \prime} \leftrightarrow \mathrm{H}_{1 \mathrm{e}}=2.44\end{array}$ & $\begin{array}{l}\mathrm{H}_{\mathrm{Na}}^{\prime} \leftrightarrow \mathrm{H}_{6 \mathrm{e}}=2.44 \\
\mathrm{H}_{\mathrm{Na}}^{\prime} \leftrightarrow \mathrm{H}_{1 \mathrm{e}}=2.44\end{array}$ & $\begin{array}{l}\left(\mathrm{N}_{\mathrm{a}} \mathrm{C}_{1} \mathrm{C}_{3} \mathrm{C}_{5}\right)=1.10 \\
\left(\mathrm{H}_{1 \mathrm{e}} \mathrm{C}_{1} \mathrm{C}_{2}\right)=-2.43\end{array}$ & $\left(\mathrm{H}_{1 \mathrm{e}} \mathrm{C}_{1} \mathrm{C}_{2} \mathrm{C}_{6}\right)=-5.17$ \\
\hline cIV & $\begin{array}{l}\mathrm{H}_{\mathrm{Na}}^{\prime \prime} \leftrightarrow \mathrm{H}_{3 \mathrm{a}}=2.31 \\
\mathrm{H}_{\mathrm{Na}}^{\prime \prime} \leftrightarrow \mathrm{H}_{5 \mathrm{e}}=2.36\end{array}$ & $\mathrm{H}_{\mathrm{Na}}^{\prime} \leftrightarrow \mathrm{H}_{1 \mathrm{e}}=2.36$ & $\begin{array}{l}\left(\mathrm{N}_{\mathrm{a}} \mathrm{C}_{1} \mathrm{C}_{3} \mathrm{C}_{5}\right)=-1.88 \\
\left(\mathrm{~N}_{\mathrm{a}} \mathrm{C}_{1} \mathrm{C}_{2}\right)=5.71\end{array}$ & $\left(\mathrm{H}_{1 \mathrm{e}} \mathrm{C}_{1} \mathrm{C}_{2}\right)=-2.07$ \\
\hline
\end{tabular}


Although some monosubstituted cyclohexanes were reported as adopting in a certain extent the axial conformation, [40] the majority exhibits equatorial preference. [39] The explanation for the axial hydrogen atom replacement would lie in the repulsive interaction between the substituent and $\mathrm{H}_{3 \mathrm{a}}$ and $\mathrm{H}_{5 \mathrm{a}}$ of cyclohexane (1,3-syn-diaxial interaction). The equatorial substituent, being away from the ring, accommodates itself easily to that orientation.

The results obtained for cyclohexylamine show effectively the equatorial preference. However, these can not be understood on the grounds of 1,3-diaxial interaction as far as they are not significant in cIII, the most stable axial conformer, but only in cIV which represents 38 per cent of the axial isomers.

It was proved, both theoretically and experimentally, that 1,3-diaxial interactions do not explain the equatorial preference of alkyl- $[10,13,14,41]$, halo- $[11,13]$ and OR[14] groups, or at least they were not the main cause. Instead, the presence of the referred substituents in the axial position affects essentially the local geometry at the substitution site, rather than remote ring positions, where no significant structural perturbations were found $[10,11,41]$.

Attending to the diversity of interactions, a detailed study of each conformation is required in order to understand the structure of the cyclohexylamine conformers either in equatorial or in axial isomers.

\section{2. cis-Cyclohexyl-1,2-diamine}

As referred above, in cis-cyclohexyl-1,2-diamine one amine group is equatorial and the other is axial. Conventionally, the carbon to which the axial $\mathrm{NH}_{2}$ is connected is numbered as 1 and the carbon bonded to equatorial $\mathrm{NH}_{2}$ numbered as 2 .

The potential energy surface of this isomer was calculated at the B3LYP/6-31G(d) level of theory and is represented as a function of $\mathrm{Lp}-\mathrm{N}_{1 \mathrm{a}}-\mathrm{C}_{1}-\mathrm{H}_{1}$ and $\mathrm{Lp}-\mathrm{N}_{2 \mathrm{e}}-\mathrm{C}_{2}-\mathrm{H}_{2}$ dihedral angles in Fig. 3. It can be observed in this surface that low energy regions correspond to staggered conformations of the amino groups. Considering that each group can adopt three approximate staggered orientations (trans, gauche and gauche'), nine areas could be expected as potential energy wells. One of these, around equatori$\mathrm{al}=180^{\circ}$ and axial $=-60^{\circ}$, is flattened by the energy increase caused by the repulsive interaction between the lone pairs on the nitrogen atoms. When the equatorial group is in a skew' position $\left(-120^{\circ}\right)$, any orientation of the axial group is unstable except gauche'. These conformations have the equatorial amino group eclipsed, with one of its hydrogen atoms pointing to the other substituent. This instability is only attenuated when the lone electron pair of the axial $\mathrm{NH}_{2}$ points to the hydrogen atom referred above.

The local minima identified on the potential energy surface were further optimized employing the aug-cc-pVDZ basis set. The electronic energy for each conformer is given in Table 4. In the same table the values for the internal

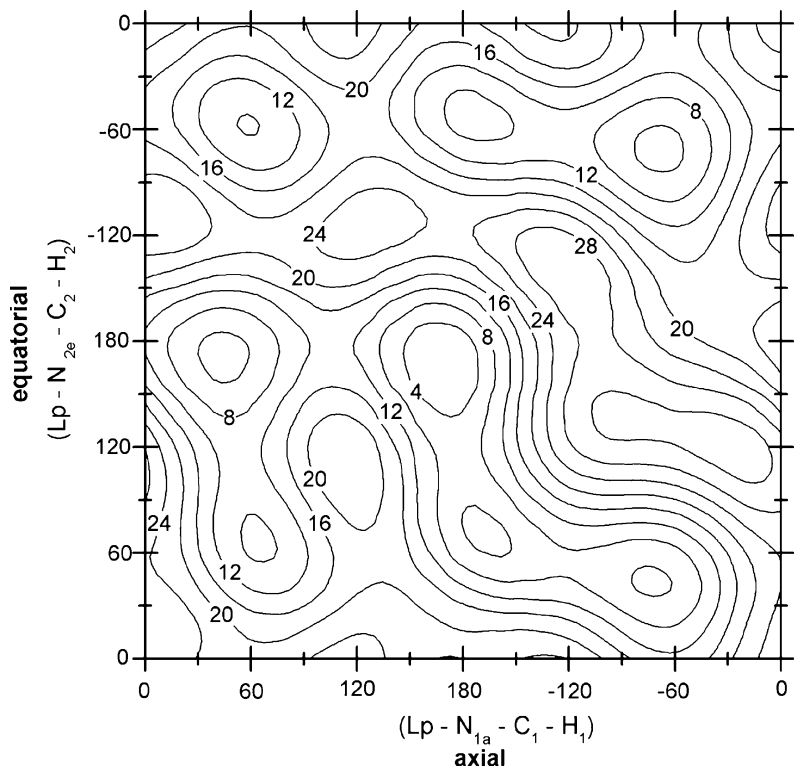

Fig. 3. B3LYP/6-31G(d) potential energy surface of cis-cyclohexyl-1,2diamine.

energy, enthalpy, entropy terms, Gibbs energy at $298.15 \mathrm{~K}$ as well as the relative population of each conformer based on the Gibbs energy are prersented. The conformers are represented in Fig. 4.

The eight conformers lie within a $7 \mathrm{~kJ} \mathrm{~mol}^{-1}$ electronic energy interval. cII is $2.5 \mathrm{~kJ} \mathrm{~mol}^{-1}$ above cI. From cII to $\mathrm{cV}$ the energy between consecutive conformers is approximately $0.5 \mathrm{~kJ} \mathrm{~mol}^{-1}$ and from $\mathrm{cV}$ to cVI is $1.2 \mathrm{~kJ} \mathrm{~mol}^{-1}$. The energy difference between cVII and cVIII is $0.81 \mathrm{~kJ} \mathrm{~mol}^{-1}$.

The lowest energy conformer is the also least entropic. The entropy variation among the conformers results mainly from the differences in the vibrational modes. Except for cIII and cIV, with entropy values of 1.0 and $1.6 \mathrm{~J} \mathrm{~K}^{-1} \mathrm{~mol}^{-1}$, respectively, relative to the global minimum, all the other conformers have entropies 3.1$3.8 \mathrm{~J} \mathrm{~K}^{-1} \mathrm{~mol}^{-1}$ higher than cI. Thus, the entropy lowers the Gibbs energy of all conformers, varying the relative population of some of them without altering the relative order given by energy.

The major repulsive $\mathrm{H} \leftrightarrow \mathrm{H}$ contacts in cis-cyclohexyl1,2-diamine, arising from the presence of the $\mathrm{NH}_{2}$ groups and the consequent variations of bond and torsion angles, are given in Table 5.

The lowest energy conformer is trans for both amine groups that is also the most favorable orientation either in equatorial- or in axial-cyclohexylamine. However, the strain in the disubstituted molecule is quite different from that in the monosubstituted one. As a consequence of the hydrogen interactions to get the minimal van der Waals repulsive energy, the dihedral angles used to characterize the $\mathrm{NH}_{2}$ orientation have a considerable negative deviation relatively to the equatorial and axial cyclohexylamines. 
Table 4

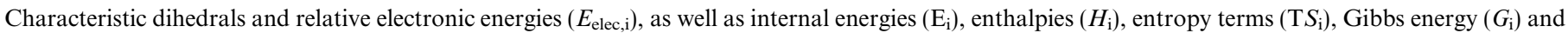
equilibrium populations $\left(P_{\mathrm{i}}\right)$ at $298.15 \mathrm{~K}$ for the B3LYP/aug-cc-pVDZ optimized structures of the conformers of cis-cyclohexyl-1,2-diamine

\begin{tabular}{|c|c|c|c|c|c|c|c|c|}
\hline Conformer & $\begin{array}{l}\left(\mathrm{Lp}-\mathrm{N}_{1 \mathrm{a}}-\mathrm{C}_{1}-\mathrm{H}_{1}\right) / \\
\operatorname{deg}\end{array}$ & $\begin{array}{l}\left(\mathrm{Lp}-\mathrm{N}_{2 \mathrm{e}}-\mathrm{C}_{2}-\mathrm{H}_{2}\right) / \\
\mathrm{deg}\end{array}$ & $E_{\text {elec,i }} /$ Hartree & $E_{\mathrm{i}} /$ Hartree & $\begin{array}{l}H_{\mathrm{i}}(298.15 \mathrm{~K}) / \\
\text { Hartree }\end{array}$ & $\begin{array}{l}\mathrm{T} S_{\mathrm{i}} / \\
\text { Hartree }\end{array}$ & $\begin{array}{l}G_{\mathrm{i}}(298.15 \mathrm{~K}) / \\
\text { Hartree }\end{array}$ & $\begin{array}{l}P_{\mathrm{i}} \\
(\%)\end{array}$ \\
\hline cI & 169.31 & 167.16 & -346.62318691 & -346.41138191 & -346.4104379 & 0.040982 & -346.4514199 & 35.8 \\
\hline cII & -166.89 & 75.29 & -346.62224050 & -346.41026550 & -346.4093215 & 0.041328 & -346.4506495 & 15.8 \\
\hline cIII & 44.88 & 170.00 & -346.62202165 & -346.41014765 & -346.4092037 & 0.041097 & -346.4503007 & 10.9 \\
\hline cIV & -78.68 & 47.64 & -346.62184341 & -346.41007341 & -346.4091294 & 0.041159 & -346.4502884 & 10.8 \\
\hline $\mathrm{cV}$ & -74.08 & -74.05 & -346.62163396 & -346.40986396 & -346.4089200 & 0.041340 & -346.4502600 & 10.5 \\
\hline cVI & -171.57 & -55.28 & -346.62117970 & -346.40949170 & -346.4085477 & 0.041333 & -346.4498807 & 7.0 \\
\hline cVII & 66.67 & 69.69 & -346.62080261 & -346.40911261 & -346.4081676 & 0.041417 & -346.4495846 & 5.1 \\
\hline cVIII & 62.93 & -58.63 & -346.62049430 & -346.40894630 & -346.4080023 & 0.041376 & -346.4493783 & 4.1 \\
\hline
\end{tabular}
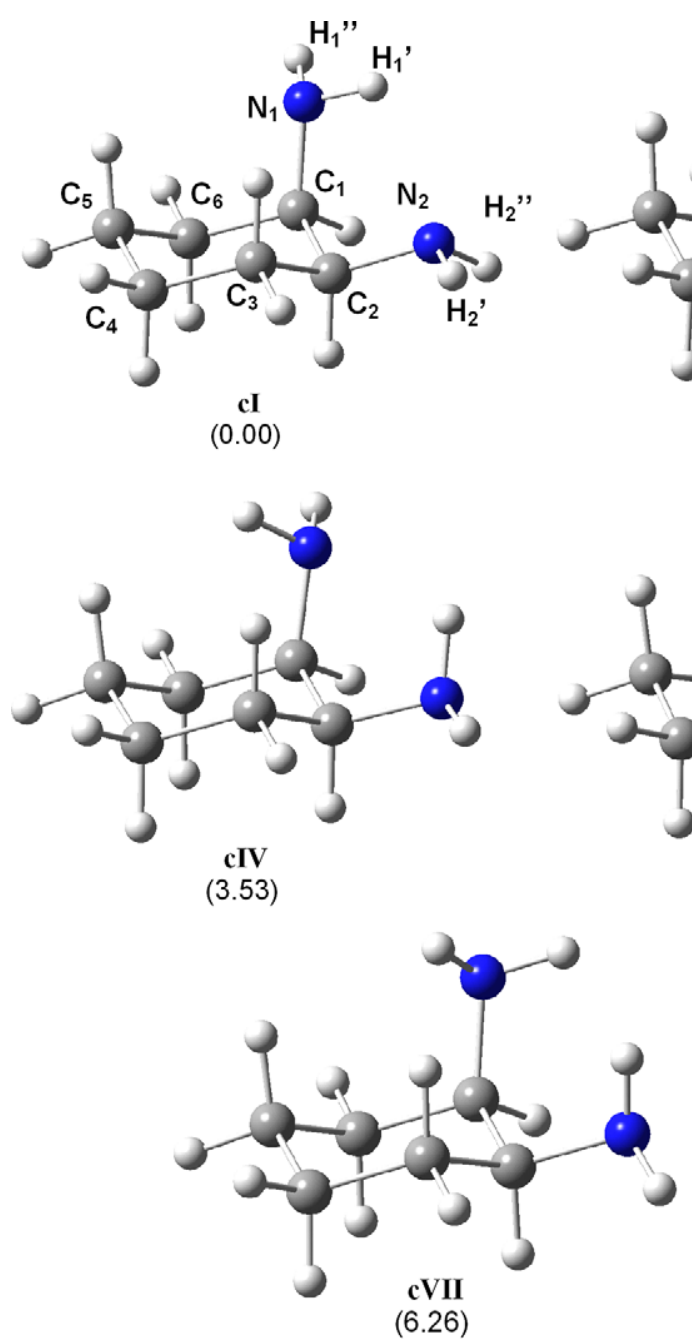
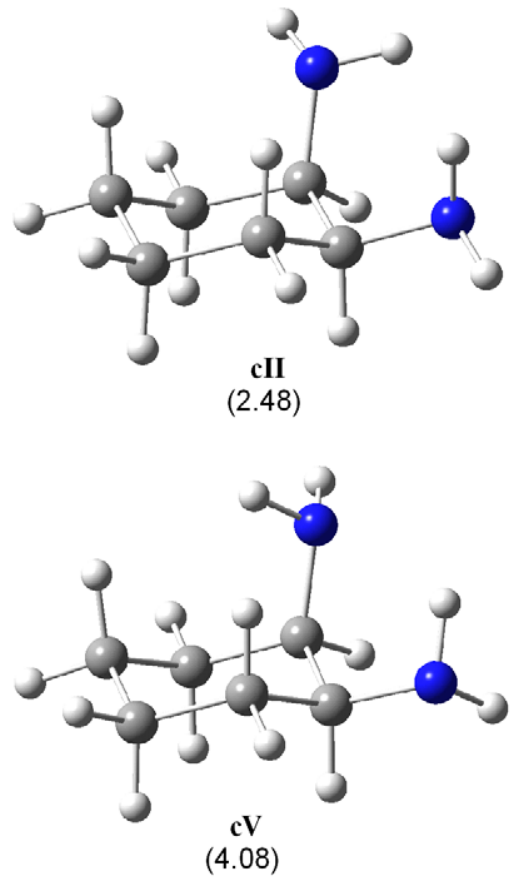
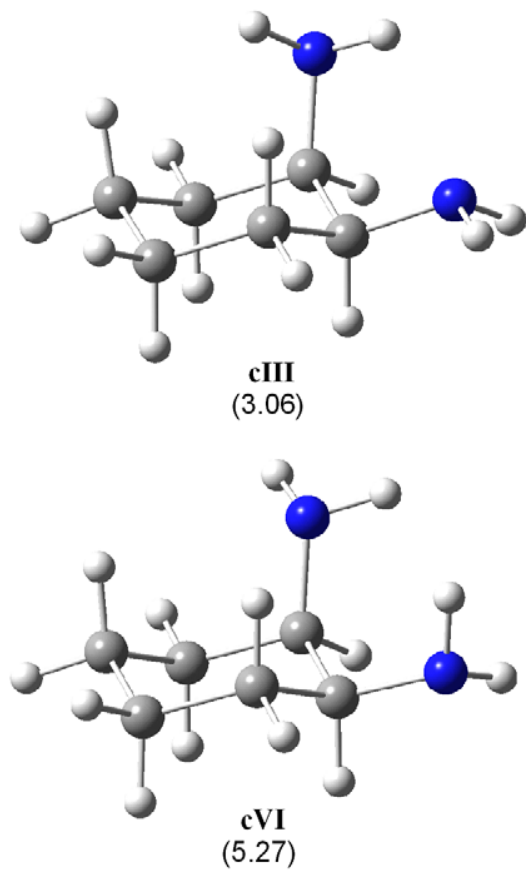

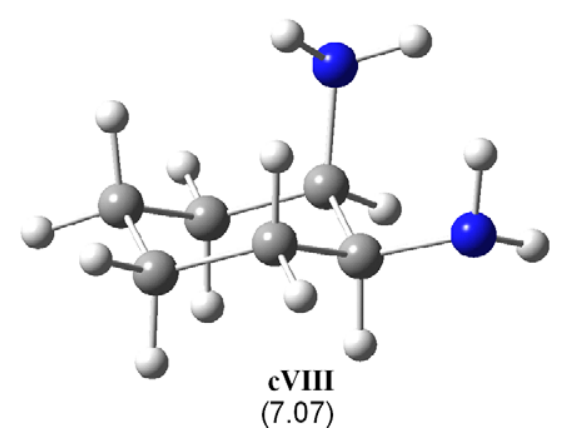

Fig. 4. B3LYP/aug-cc-pVDZ optimized geometries of the conformers of cis-cyclohexyl-1,2-diamine. The values in parenthesis represent the energy relatively to the most stable conformer in $\mathrm{kJ} \mathrm{mol}^{-1}$.

Indeed, the hydrogen atoms of both $\mathrm{NH}_{2}$ contribute to the destabilization energy of all conformers by interacting with the hydrogen atoms of the cyclohexyl ring or between themselves.

The capacity of the amino group to participate in hydrogen bonds either as hydrogen donor or acceptor raises the pertinent question whether this type of interaction exists in cis-cyclohexyl-1,2-diamine. The two amine groups can be involved in an intra-homonuclear hydrogen bond contributing to the structure stabilization. A common definition of hydrogen bond in geometrical terms is based on the $(\mathrm{H} \cdots \mathrm{A})$ distance and on $(\mathrm{D}-\mathrm{H} \cdots \mathrm{A})$ angle, where $\mathrm{D}$ is 
Table 5

Main differences for angles and dihedrals between cis-cyclohexyl-1,2-diamine and cyclohexane and the values for $\mathrm{H}-\mathrm{H}$ distances

\begin{tabular}{|c|c|c|c|c|}
\hline \multirow{2}{*}{$\begin{array}{l}\text { Conformer } \\
\mathrm{cI}\end{array}$} & \multicolumn{2}{|c|}{ Non-bonded H-H distances/Å } & \multicolumn{2}{|c|}{ Variation of bond and torsion angles/deg } \\
\hline & $\begin{array}{l}\mathrm{H}_{\mathrm{N1a}}^{\prime} \leftrightarrow \mathrm{H}_{1 \mathrm{e}}=2.39 \\
\mathrm{H}_{\mathrm{N} 2 \mathrm{e}}^{\prime \prime} \leftrightarrow \mathrm{H}_{2 \mathrm{a}}=2.37\end{array}$ & $\mathrm{H}_{\mathrm{N} 2 \mathrm{e}}^{\prime} \leftrightarrow \mathrm{H}_{3 \mathrm{e}}=2.41$ & $\left(\mathrm{~N}_{1 \mathrm{a}} \mathrm{C}_{1} \mathrm{H}_{1 \mathrm{e}}\right)=5.36$ & $\left(\mathrm{~N}_{2 \mathrm{e}} \mathrm{C}_{2} \mathrm{H}_{2 \mathrm{a}}\right)=5.04$ \\
\hline cII & $\begin{array}{l}\mathrm{H}_{\mathrm{N} 1 \mathrm{a}}^{\prime \prime} \leftrightarrow \mathrm{H}_{\mathrm{N} 2 \mathrm{e}}^{\prime}=2.34 \\
\mathrm{H}_{\mathrm{N} 1 \mathrm{a}}^{\prime} \leftrightarrow \mathrm{H}_{6 \mathrm{e}}=2.37\end{array}$ & $\mathrm{H}_{\mathrm{N} 2 \mathrm{e}}^{\prime \prime} \leftrightarrow \mathrm{H}_{2 \mathrm{a}}=2.29$ & $\left(\mathrm{~N}_{1 \mathrm{a}} \mathrm{C}_{1} \mathrm{H}_{1 \mathrm{e}}\right)=4.68$ & $\left(\mathrm{~N}_{2 \mathrm{e}} \mathrm{C}_{2} \mathrm{H}_{2 \mathrm{a}}\right)=3.70$ \\
\hline cIII & $\mathrm{H}_{\mathrm{N} 1 \mathrm{a}}^{\prime \prime} \leftrightarrow \mathrm{H}_{5 \mathrm{a}}=2.21$ & $\mathrm{H}_{\mathrm{N} 2 \mathrm{e}}^{\prime \prime} \leftrightarrow \mathrm{H}_{2 \mathrm{a}}=2.39$ & $\begin{array}{l}\left(\mathrm{N}_{1 \mathrm{a}} \mathrm{C}_{1} \mathrm{C}_{3} \mathrm{C}_{5}\right)=2.08 \\
\left(\mathrm{~N}_{2 \mathrm{e}} \mathrm{C}_{2} \mathrm{H}_{2 \mathrm{a}}\right)=5.15\end{array}$ & $\left(\mathrm{~N}_{1 \mathrm{a}} \mathrm{C}_{1} \mathrm{C}_{2}\right)=5.59$ \\
\hline cIV & $\mathrm{H}_{\mathrm{N} 1 \mathrm{a}}^{\prime} \leftrightarrow \mathrm{H}_{5 \mathrm{a}}=2.23$ & $\mathrm{H}_{\mathrm{N} 2 \mathrm{e}}^{\prime \prime} \leftrightarrow \mathrm{H}_{1 \mathrm{e}}=2.26$ & $\begin{array}{l}\left(\mathrm{N}_{1 \mathrm{a}} \mathrm{C}_{1} \mathrm{C}_{3} \mathrm{C}_{5}\right)=5.70 \\
\left(\mathrm{~N}_{2 \mathrm{e}} \mathrm{C}_{2} \mathrm{C}_{4} \mathrm{C}_{6}\right)=5.16\end{array}$ & $\begin{array}{l}\left(\mathrm{N}_{1 \mathrm{a}} \mathrm{C}_{2} \mathrm{C}_{6}\right)=5.37 \\
\left(\mathrm{~N}_{2 \mathrm{e}} \mathrm{C}_{2} \mathrm{C}_{3}\right)=5.25\end{array}$ \\
\hline $\mathrm{cV}$ & $\begin{array}{l}\mathrm{H}_{\mathrm{N} 1 \mathrm{a}}^{\prime} \leftrightarrow \mathrm{H}_{5 \mathrm{a}}=2.24 \\
\mathrm{H}_{\mathrm{N} 1 \mathrm{a}}^{\prime \prime} \leftrightarrow \mathrm{H}_{1 \mathrm{e}}=2.28\end{array}$ & $\begin{array}{l}\mathrm{H}_{\mathrm{N1a}}^{\prime} \leftrightarrow \mathrm{H}_{3 \mathrm{a}}=2.40 \\
\mathrm{H}_{\mathrm{N} 2 \mathrm{e}}^{\prime} \leftrightarrow \mathrm{H}_{2 \mathrm{a}}=2.30\end{array}$ & $\begin{array}{l}\left(\mathrm{N}_{1 \mathrm{a}} \mathrm{C}_{1} \mathrm{C}_{3} \mathrm{C}_{5}\right)=5.60 \\
\left(\mathrm{~N}_{2 \mathrm{e}} \mathrm{C}_{2} \mathrm{C}_{4} \mathrm{C}_{6}\right)=8.65\end{array}$ & $\begin{array}{l}\left(\mathrm{N}_{1 \mathrm{a}} \mathrm{C}_{2} \mathrm{C}_{6}\right)=5.56 \\
\left(\mathrm{~N}_{2 \mathrm{e}} \mathrm{C}_{2} \mathrm{C}_{1}\right)=4.04\end{array}$ \\
\hline $\mathrm{cVI}$ & $\begin{array}{l}\mathrm{H}_{\mathrm{N} 1 \mathrm{a}}^{\prime \prime} \leftrightarrow \mathrm{H}_{\mathrm{N} 2 \mathrm{e}}^{\prime \prime}=2.31 \\
\mathrm{H}_{\mathrm{N} 1 \mathrm{a}}^{\prime \prime} \leftrightarrow \mathrm{H}_{1 \mathrm{e}}=2.39\end{array}$ & $\mathrm{H}_{\mathrm{Nla}}^{\prime} \leftrightarrow \mathrm{H}_{6 \mathrm{e}}=2.39$ & $\begin{array}{l}\left(\mathrm{N}_{2 \mathrm{e}} \mathrm{C}_{2} \mathrm{C}_{4} \mathrm{C}_{6}\right)=8.75 \\
\left(\mathrm{~N}_{2 \mathrm{e}} \mathrm{C}_{2} \mathrm{C}_{1}\right)=4.76\end{array}$ & $\left(\mathrm{~N}_{1 \mathrm{a}} \mathrm{C}_{1} \mathrm{H}_{1 \mathrm{e}}\right)=4.97$ \\
\hline cVII & $\begin{array}{l}\mathrm{H}_{\mathrm{N} 1 \mathrm{a}}^{\prime \prime} \leftrightarrow \mathrm{H}_{3 \mathrm{a}}=2.35 \\
\mathrm{H}_{\mathrm{N} 1 \mathrm{a}}^{\prime} \leftrightarrow \mathrm{H}_{\mathrm{N} 2 \mathrm{e}}^{\prime}=2.37\end{array}$ & $\mathrm{H}_{\mathrm{N} 1 \mathrm{a}}^{\prime \prime} \leftrightarrow \mathrm{H}_{5 \mathrm{a}}=2.37$ & $\begin{array}{l}\left(\mathrm{N}_{2 \mathrm{e}} \mathrm{C}_{2} \mathrm{C}_{4} \mathrm{C}_{6}\right)=3.95 \\
\left(\mathrm{~N}_{2 \mathrm{e}} \mathrm{C}_{2} \mathrm{C}_{3}\right)=4.32\end{array}$ & $\left(\mathrm{~N}_{1 \mathrm{a}} \mathrm{C}_{1} \mathrm{C}_{2}\right)=5.97$ \\
\hline cVIII & $\begin{array}{l}\mathrm{H}_{\mathrm{N} 1 \mathrm{a}}^{\prime \prime} \leftrightarrow \mathrm{H}_{3 \mathrm{a}}=2.35 \\
\mathrm{H}_{\mathrm{N} 1 \mathrm{a}}^{\prime} \leftrightarrow \mathrm{H}_{1 \mathrm{e}}=2.34 \\
\mathrm{H}_{\mathrm{N} 2 \mathrm{e}}^{\prime} \leftrightarrow \mathrm{H}_{2 \mathrm{a}}=2.38\end{array}$ & $\begin{array}{l}\mathrm{H}_{\mathrm{N} 1 \mathrm{a}}^{\prime \prime} \leftrightarrow \mathrm{H}_{5 \mathrm{a}}=2.31 \\
\mathrm{H}_{\mathrm{N} 1 \mathrm{a}}^{\prime \prime} \leftrightarrow \mathrm{H}_{\mathrm{N} 2}^{\prime \prime}=2.35\end{array}$ & $\begin{array}{l}\left(\mathrm{N}_{2 \mathrm{e}} \mathrm{C}_{2} \mathrm{C}_{4} \mathrm{C}_{6}\right)=10.34 \\
\left(\mathrm{~N}_{2 \mathrm{e}} \mathrm{C}_{2} \mathrm{C}_{1}\right)=5.11\end{array}$ & $\left(\mathrm{~N}_{1 \mathrm{a}} \mathrm{C}_{1} \mathrm{C}_{2}\right)=6.50$ \\
\hline
\end{tabular}

Table 6

Hydrogen bonding in cis-cyclohexyl-1,2-diamine

\begin{tabular}{llll}
\hline Conformer & Bond & $\mathrm{d}(\mathrm{H} \cdots \mathrm{N}) / \AA$ & $\alpha(\mathrm{N}-\mathrm{H} \cdots \mathrm{N}) / \mathrm{deg}$ \\
\hline cI & $\mathrm{N}_{1 \mathrm{a}}-\mathrm{H}_{1}^{\prime} \cdots \mathrm{N}_{2 \mathrm{e}}$ & 2.38 & 107 \\
cIII & $\mathrm{N}_{1 \mathrm{a}}-\mathrm{H}_{1}^{\prime \prime} \cdots \mathrm{N}_{2 \mathrm{e}}$ & 2.44 & 108 \\
$\mathrm{cIV}$ & $\mathrm{N}_{2 \mathrm{e}}-\mathrm{H}_{2}^{\prime} \cdots \mathrm{N}_{1 \mathrm{a}}$ & 2.40 & 105 \\
$\mathrm{cV}$ & $\mathrm{N}_{2 \mathrm{e}}-\mathrm{H}_{2}^{\prime \prime} \cdots \mathrm{N}_{1 \mathrm{a}}$ & 2.46 & 107 \\
\hline
\end{tabular}

the donor and A is the acceptor atom. Distances up to 3.0 or even $3.2 \AA$ are able to originate hydrogen bonding $[42,43]$. Directionality is a characteristic of the hydrogen bond, being the linear or close to linear the preferred geometry. However, as a soft interaction, its intensity is still worth considering at deviations a good deal out of the preferential angular value. The angular cutoff is then $>90^{\circ}$, although $110^{\circ}$ is a commonly accepted limit [43].

Various authors $[44,45]$ stressed the difficulty to set up a threshold between an attractive interaction by hydrogen bonding and an isotropic van der Waals interaction due to short distances, arising from the overall balance of the intramolecular forces.

All conformers of cis-cyclohexyl-1,2-diamine exhibit $\mathrm{NH} \cdots \mathrm{N}$ distances ranging from 2.39 to $2.82 \AA$ and $\mathrm{N}-$ $\mathrm{H} \cdots \mathrm{N}$ angles between $108^{\circ}$ and $93^{\circ}$. Plotting angular values as a function of distances, two distinct structural groups are observed. The first is characterized by angular values ranging from $93^{\circ}$ to $96^{\circ}$ and distances from 2.68 to $2.82 \AA$; the second by higher angles $\left(105-108^{\circ}\right)$ and shorter distances $(2.39-2.46 \AA)$. The structures included in the first group are out of the hydrogen bond criterion mentioned above, while those included in the second group and specified in Table 6 may be considered as borderline cases. However, they do not play a significant role in the structure of the conformers.

\section{3. trans-Cyclohexyl-1,2-diamine}

trans-1,2-disubstituted cyclohexane can be present in a diequatorial or a diaxial conformation. In 1,2-alkyldisubstituted, diequatorial conformations predominate over the diaxial ones. [5] However, this is not a general rule, as most 1,2-dihalocyclohexanes have a diaxial structure [46]. As it will be proved later, in trans-cyclohexyl-1,2-diamine, the diaxial conformation is practically non-existent.

The potential energy surface of trans-cyclohexyl-1,2-diamine, depicted in Fig. 5, shows the existence of eight local minima. Like cis-cyclohexyl-1,2-diamine, one of the nine areas expected as potential energy wells does not really exist, apparently owing to the repulsive interaction between

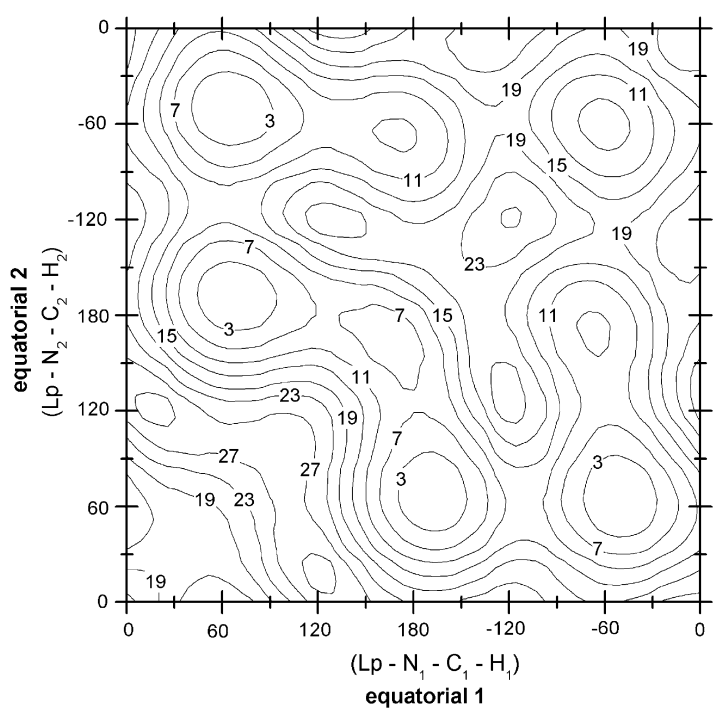

Fig. 5. B3LYP/6-31G(d) potential energy surface of trans-cyclohexyl-1,2diamine. 
the lone electron pairs of the two nitrogen atoms. It would correspond to $\left(60^{\circ}, 60^{\circ}\right)$ area. The 1,2-diequatorial conformation of the amine groups makes the minima repulsive interactions between the hydrogen atoms and also between the lone electron pairs occur at $60^{\circ},-60^{\circ}$ and $180^{\circ}$ orientation. Hence, a twofold degenerated state is observed for three conformers. The degeneracy is clearly shown by the potential energy surface as the position of the degenerated conformers are symmetric relatively to the diagonal line defined by $\left(180^{\circ}, 180^{\circ}\right)$ and $\left(-60^{\circ},-60^{\circ}\right)$.

The five non-degenerated structures were reoptimized with the basis set used for the other cyclohexane derivatives. In Table 7 are given the values calculated for the electronic energy of each conformer as well as the values calculated for the internal energy, enthalpy, entropy terms, Gibbs energy and population at $298.15 \mathrm{~K}$. The structures of these conformers are represented in Fig. 6.

Six conformers are defined for a diaxial isomer of trans1,2-diaminocyclohexane. However, the electronic energy of the most stable of them is about $13 \mathrm{~kJ}$ above the global minimum, which corresponds to a relative population of $0.08 \%$. Thus, only the diequatorial conformations were considered.

The five conformers of trans-cyclohexyl-1,2-diamine lie within a $5.11 \mathrm{~kJ} \mathrm{~mol}^{-1}$ energy range. The greater energy differences between two next neighbor conformers are observed between cI and cII $\left(1.30 \mathrm{~kJ} \mathrm{~mol}^{-1}\right)$ and cIII and cIV $\left(2.18 \mathrm{~kJ} \mathrm{~mol}^{-1}\right)$. The energy difference between cII and cIII and cIV and $\mathrm{cV}$ are smaller than $1 \mathrm{~kJ} \mathrm{~mol}^{-1}$.

The entropy variation between conformers of this isomer is mainly due to differences in the degeneracy degree. Thus, the entropic term makes a decrease of Gibbs energy of the doubly degenerated conformers (cI, cII and cIV) relatively to the non-degenerated ones (cIII and cV). An inversion between cIII and cIV in the relative ordering by Gibbs energy occurs because of the entropic contribution.

The trans-cyclohexyldiamine is more stable than the cisisomer. All conformers of the former have lower energies than the global minimum of the latter. The values of the thermodynamic properties of the cis isomer, relatively to

Table 7

Characteristic dihedrals and relative electronic energies $\left(E_{\mathrm{elec}, \mathrm{i}}\right)$, as well as internal energies $\left(E_{\mathrm{i}}\right)$, enthalpies $\left(H_{\mathrm{i}}\right)$, entropy terms $\left(T S_{\mathrm{i}}\right)$, Gibbs energy $\left(G_{\mathrm{i}}\right)$ and equilibrium populations $\left(P_{\mathrm{i}}\right)$ at $298.15 \mathrm{~K}$ for the B3LYP/aug-cc-pVDZ optimized structures of the conformers of trans-cyclohexyl-1,2-diamine

\begin{tabular}{|c|c|c|c|c|c|c|c|c|}
\hline Conformer & $\begin{array}{l}\left(\mathrm{Lp}-\mathrm{N}_{1}-\mathrm{C}_{1}-\mathrm{H}_{1}\right) / \\
\operatorname{deg}\end{array}$ & $\begin{array}{l}\left(\mathrm{Lp}-\mathrm{N}_{2}-\mathrm{C}_{2}-\mathrm{H}_{2}\right) / \\
\operatorname{deg}\end{array}$ & $E_{\text {elec }, i} / \mathrm{kJ} \mathrm{mol}^{-1}$ & $E_{\mathrm{i}} /$ Hartree & $\begin{array}{l}H_{\mathrm{i}}(298.15 \mathrm{~K}) / \\
\text { Hartree }\end{array}$ & $\begin{array}{l}\mathrm{T} S_{\mathrm{i}} / \\
\text { Hartree }\end{array}$ & $\begin{array}{l}G_{\mathrm{i}}(298.15 \mathrm{~K}) / \\
\text { Hartree }\end{array}$ & $P_{\mathrm{i}}(\%)^{\mathrm{a}}$ \\
\hline cI & 69.94 & -172.85 & -346.62523403 & -346.41361703 & -346.41267303 & 0.041902 & -346.45457545 & $46.7(2)$ \\
\hline cII & 67.60 & -47.60 & -346.62473840 & -346.41309840 & -346.41215440 & 0.042025 & -346.45417982 & $30.7(2)$ \\
\hline cIV & 168.14 & -66.17 & -346.62361950 & -346.41201650 & -346.41107250 & 0.042052 & -346.45312492 & $10.0(2)$ \\
\hline $\mathrm{cV}$ & -61.28 & -61.11 & -346.62328670 & -346.41183570 & -346.41089170 & 0.041434 & -346.45232570 & $4.3(1)$ \\
\hline
\end{tabular}

${ }^{\mathrm{a}}$ Numbers in parenthesis correspond to the degeneracy degree of conformers.

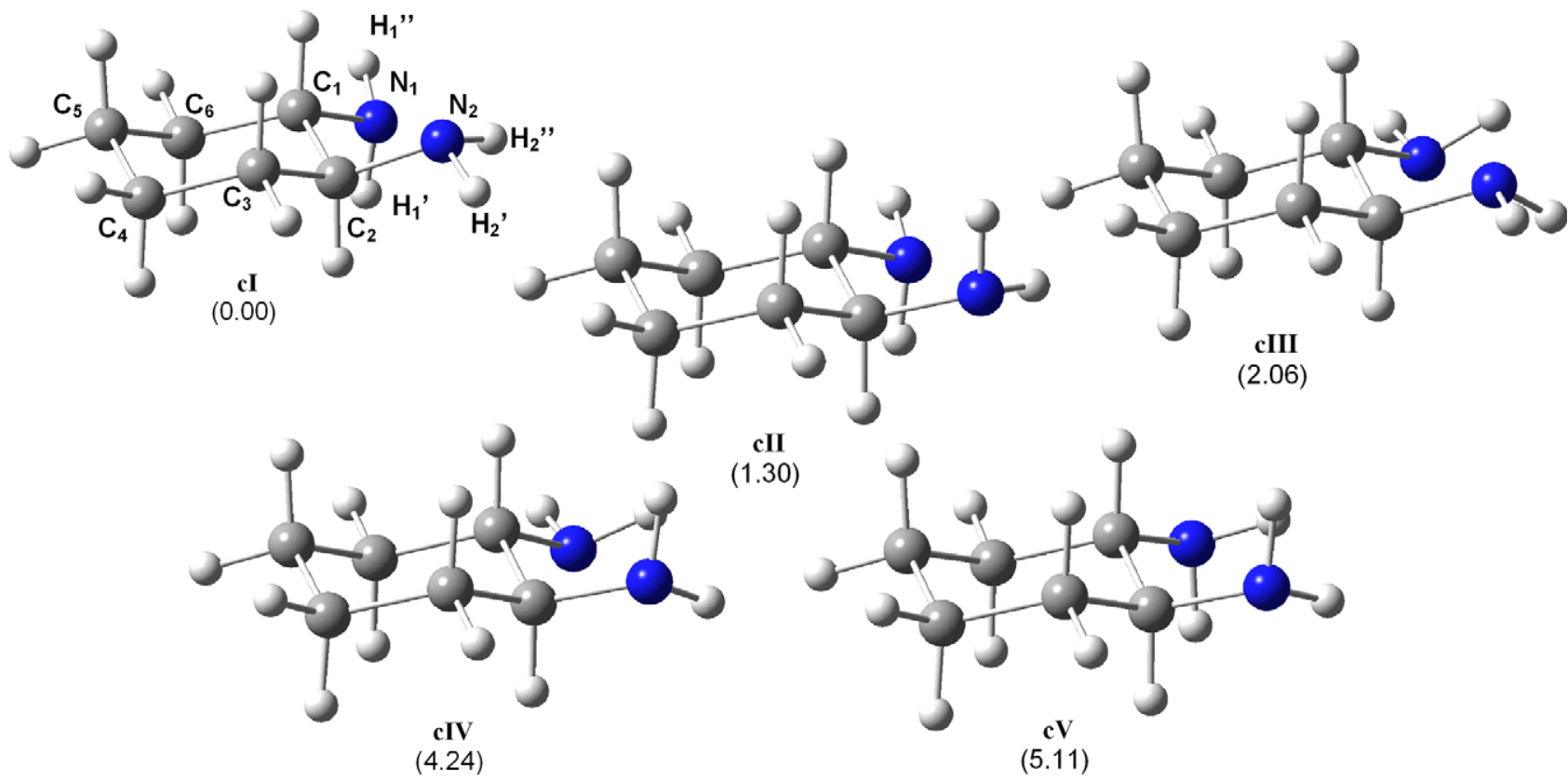

Fig. 6. B3LYP/aug-cc-pVDZ optimized geometries of the conformers of trans-cyclohexyl-1,2-diamine. The values in parenthesis represent the energy relatively to the most stable conformer in $\mathrm{kJ} \mathrm{mol}^{-1}$. 
those of the trans at $298.15 \mathrm{~K}$, calculated from the data given in Tables 3 and 5, are: $\Delta H=7.117 \mathrm{~kJ} \mathrm{~mol}^{-1}$, $T \Delta S=-1.888 \mathrm{~kJ} \mathrm{~mol}^{-1}$ and $\Delta G=9.005 \mathrm{~kJ} \mathrm{~mol}^{-1}$.

Similarly to what was done for the characterization of the two other cyclohexane derivatives in structural terms, a table stating the short $\mathrm{H} \leftrightarrow \mathrm{H}$ distances and the main variations of the angles by replacement of two equatorial hydrogens of cyclohexane by two amine groups was built (Table 8).

Although the interpretation of the trans-cyclohexylamine has to consider the simultaneous conformational behavior of both amine groups, it is possible to discriminate some features assigned to the conformations of each group. In spite of the mutual effect of the amine groups, the influence on the structure of certain conformation of each one is sometimes dominant.

The gauche $\mathrm{Lp}-\mathrm{N}_{1 \mathrm{e}}-\mathrm{C}_{1}-\mathrm{H}_{1}$ torsion (cI and cII) gives rise to steric strain between $\mathrm{H}_{\mathrm{N} 1 \mathrm{e}}^{\prime \prime}$ and $\mathrm{H}_{1 \mathrm{a}}$ and to a positive deviation of the $\mathrm{N}_{1 \mathrm{e}}-\mathrm{C}_{1}-\mathrm{C}_{6}$ angle relatively to cyclohexane. When this dihedral is trans (cIII and cIV), the repulsive interactions between hydrogen pairs $\mathrm{H}_{\mathrm{N} 1 \mathrm{e}}^{\prime} \leftrightarrow \mathrm{H}_{6 \mathrm{e}}$ and $\mathrm{H}_{\mathrm{N} 1 \mathrm{e}}^{\prime \prime} \leftrightarrow \mathrm{H}_{1 \mathrm{a}}$ occur, which are accompanied by a pronounced positive deviation of the $\mathrm{N}_{1 \mathrm{e}}-\mathrm{C}_{1}-\mathrm{H}_{1 \mathrm{a}}$ angle. The gauche' configuration of $\mathrm{Lp}-\mathrm{N}_{1 \mathrm{e}}-\mathrm{C}_{2}-\mathrm{H}_{2}(\mathrm{cV})$ distorts the structure mostly by an increase of the $\mathrm{N}_{1 \mathrm{e}} \mathrm{C}_{1} \mathrm{C}_{3} \mathrm{C}_{5}$ dihedral angle.

The other amine group $\left(\mathrm{N}_{2 \mathrm{e}} \mathrm{H}_{2}\right)$ can have trans or gauche characteristic torsion ( $\mathrm{Lp}-\mathrm{N}_{2 \mathrm{e}}-\mathrm{C}_{2}-\mathrm{H}_{2}$ ) configurations. In the first case (cI and cIII), although their $\mathrm{H} \leftrightarrow \mathrm{H}$ contacts are different, they share a significant opening of the $\mathrm{N}_{2 \mathrm{e}}-\mathrm{C}_{2}-\mathrm{H}_{2 \mathrm{a}}$ angle. Finally, gauche $\mathrm{Lp}-\mathrm{N}_{2 \mathrm{e}}-\mathrm{C}_{2}-$ $\mathrm{H}_{2}$ conformers (cII, cIV and $\mathrm{cV}$ ) exhibit high positive distortions in $\mathrm{N}_{2 \mathrm{e}}-\mathrm{C}_{2}-\mathrm{C}_{4}-\mathrm{C}_{6}$ dihedral and the $\mathrm{N}_{2 \mathrm{e}}-\mathrm{C}_{2}-\mathrm{C}_{1}$ angle, relatively to the cyclohexane structure, caused by different hydrogen atom repulsions.

Like the cis isomer, all conformers of trans-cyclohexyl1,2-diamine present $\mathrm{NH} \cdots \mathrm{N}$ distances within the range of values favorable to the establishment of intramolecular hydrogen bonds. Again, the angular values are close or below the conventional cutoff. Following an identical reasoning to that described for cis-cyclohexyl-1,2-diamine,
Table 9

Hydrogen bonding in trans-cyclohexyl-1,2-diamine

\begin{tabular}{llll}
\hline Conformer & Bond & $\mathrm{d}(\mathrm{H} \cdots \mathrm{N}) / \AA$ & $\alpha(\mathrm{N}-\mathrm{H} \cdots \mathrm{N}) / \mathrm{deg}$ \\
\hline cI & $\mathrm{N}_{2 \mathrm{e}}-\mathrm{H}_{2}^{\prime \prime} \cdots \mathrm{N}_{\mathrm{le}}$ & 2.40 & 106 \\
cII & $\mathrm{N}_{2 \mathrm{e}}-\mathrm{H}_{2}^{\prime} \cdots \mathrm{N}_{\mathrm{le}}$ & 2.45 & 107 \\
\hline
\end{tabular}

the two $\mathrm{NH} \cdots \mathrm{N}$ interactions given in Table 9 can be considered as weak hydrogen bond interactions.

\section{Conclusions}

The structure of the conformers of the mono- and 1,2aminoderivatives of cyclohexane was determined at B3LYP/aug-cc-pVDZ calculation level and the structure characterized by the geometrical coordinates and thermodynamic functions. Cyclohexylamine is present in equatorial or axial isomeric forms, each of them consisting of two conformers. At $298.15 \mathrm{~K}$, the equatorial isomer represents $95 \%$ of the overall population.

The cis-cyclohexyl-1,2-diamine isomer has eight conformers, comprising a range of $5.4 \mathrm{~kJ} \mathrm{~mol}^{-1}$ in Gibbs energy, whereas the trans has five diequatorial conformers differing of at most of $5.9 \mathrm{~kJ} \mathrm{~mol}^{-1}$ in free energy (corresponding to relative populations between $46.7 \%$ and $4.3 \%$ ).

Internal energy, enthalpy, entropy, free energy and relative populations are given for each conformer at $298.15 \mathrm{~K}$.

Short $\mathrm{H} \leftrightarrow \mathrm{H}$ contacts imposed to accommodate the amine substituents connected to the cyclohexane ring give rise to distortions in the original strainless structure. These steric repulsions of the cyclohexane aminic derivatives determine the number of conformers and their energy.

The 1,2 position of the amine groups in the diamines do not favor the directional preferences for intramolecular hydrogen bonding. Nevertheless, the donor-hydrogen-acceptor angle is in some conformers of cis and trans isomers close to the cutoff conventionally adopted for the existence of this type of bond. However it should be stressed that the steric effects remain the dominant interaction ruling the

Table 8

Main differences for angles and dihedrals between trans-cyclohexyl-1,2-diamine and cyclohexane and the values for $\mathrm{H}-\mathrm{H}$ distances

\begin{tabular}{|c|c|c|c|c|}
\hline \multirow{2}{*}{$\begin{array}{l}\text { Conformer } \\
\mathrm{cI}\end{array}$} & \multirow{2}{*}{\multicolumn{2}{|c|}{$\begin{array}{l}\text { Non-bonded H-H distances/Å } \\
\mathrm{H}_{\mathrm{N} 1 \mathrm{e}}^{\prime \prime} \leftrightarrow \mathrm{H}_{1 \mathrm{a}}=2.32\end{array}$}} & \multicolumn{2}{|c|}{ Variation of bond and torsion angles/deg } \\
\hline & & & $\begin{array}{l}\left(\mathrm{N}_{1 \mathrm{e}} \mathrm{C}_{1} \mathrm{C}_{6}\right)=4.80 \\
\left(\mathrm{~N}_{2 \mathrm{e}} \mathrm{C}_{2} \mathrm{H}_{2 \mathrm{a}}\right)=5.69\end{array}$ & $\left(\mathrm{~N}_{2 \mathrm{e}} \mathrm{C}_{2} \mathrm{C}_{4} \mathrm{C}_{6}\right)=-3.78$ \\
\hline cII & $\mathrm{H}_{\mathrm{N} 1 \mathrm{e}}^{\prime \prime} \leftrightarrow \mathrm{H}_{1 \mathrm{a}}=2.33$ & $\mathrm{H}_{\mathrm{N} 1 \mathrm{e}}^{\prime} \leftrightarrow \mathrm{H}_{3 \mathrm{a}}=2.40$ & $\begin{array}{l}\left(\mathrm{N}_{1 \mathrm{e}} \mathrm{C}_{1} \mathrm{C}_{6}\right)=4.99 \\
\left(\mathrm{~N}_{2 \mathrm{e}} \mathrm{C}_{2} \mathrm{C}_{1}\right)=4.04\end{array}$ & $\left(\mathrm{~N}_{2 \mathrm{e}} \mathrm{C}_{2} \mathrm{C}_{4} \mathrm{C}_{6}\right)=6.31$ \\
\hline cIII & $\begin{array}{l}\mathrm{H}_{\mathrm{N} 1 \mathrm{e}}^{\prime} \leftrightarrow \mathrm{H}_{6 \mathrm{a}}=2.39 \\
\mathrm{H}_{\mathrm{N} 1 \mathrm{e}}^{\prime} \leftrightarrow \mathrm{H}_{\mathrm{N} 2 \mathrm{e}}^{\prime}=2.34 \\
\mathrm{H}_{\mathrm{N} 2 \mathrm{e}}^{\prime} \leftrightarrow \mathrm{H}_{2 \mathrm{a}}=2.33\end{array}$ & $\begin{array}{l}\mathrm{H}_{\mathrm{N} 1 \mathrm{e}}^{\prime \prime} \leftrightarrow \mathrm{H}_{1 \mathrm{a}}=2.34 \\
\mathrm{H}_{\mathrm{N} 2 \mathrm{e}}^{\prime \prime} \leftrightarrow \mathrm{H}_{3 \mathrm{e}}=2.39\end{array}$ & $\left(\mathrm{~N}_{1 \mathrm{e}} \mathrm{C}_{1} \mathrm{H}_{1 \mathrm{a}}\right)=4.96$ & $\left(\mathrm{~N}_{2 \mathrm{e}} \mathrm{C}_{2} \mathrm{H}_{2 \mathrm{a}}\right)=4.97$ \\
\hline cIV & $\begin{array}{l}\mathrm{H}_{\mathrm{N} 1 \mathrm{e}}^{\prime} \leftrightarrow \mathrm{H}_{6 \mathrm{e}}=2.39 \\
\mathrm{H}_{\mathrm{N} 1 \mathrm{e}}^{\prime \prime} \leftrightarrow \mathrm{H}_{\mathrm{N} 2 \mathrm{e}}^{\prime \prime}=2.31\end{array}$ & $\begin{array}{l}\mathrm{H}_{\mathrm{N} 1 \mathrm{e}}^{\prime \prime} \leftrightarrow \mathrm{H}_{1 \mathrm{a}}=2.38 \\
\mathrm{H}_{\mathrm{N} 2}^{\prime \prime} \leftrightarrow \mathrm{H}_{2 \mathrm{a}}=2.33\end{array}$ & $\begin{array}{l}\left(\mathrm{N}_{1 \mathrm{e}} \mathrm{C}_{1} \mathrm{H}_{1 \mathrm{a}}\right)=5.32 \\
\left(\mathrm{~N}_{2 \mathrm{e}} \mathrm{C}_{2} \mathrm{C}_{1}\right)=4.75\end{array}$ & $\left(\mathrm{~N}_{2 \mathrm{e}} \mathrm{C}_{2} \mathrm{C}_{4} \mathrm{C}_{6}\right)=8.36$ \\
\hline $\mathrm{cV}$ & $\mathrm{H}_{\mathrm{N} 2 \mathrm{e}}^{\prime \prime} \leftrightarrow \mathrm{H}_{\mathrm{N} 1 \mathrm{e}}^{\prime}=2.28$ & & $\begin{array}{l}\left(\mathrm{N}_{1 \mathrm{e}} \mathrm{C}_{1} \mathrm{C}_{2}\right)=6.01 \\
\left(\mathrm{~N}_{2 \mathrm{e}} \mathrm{C}_{2} \mathrm{C}_{1}\right)=4.97\end{array}$ & $\left(\mathrm{~N}_{2 \mathrm{e}} \mathrm{C}_{2} \mathrm{C}_{4} \mathrm{C}_{6}\right)=7.73$ \\
\hline
\end{tabular}


conformational landscapes of the cyclohexane aminic derivatives.

\section{Appendix A. Supplementary data}

Supplementary data associated with this article can be found, in the online version, at doi:10.1016/ j.theochem.2006.09.035.

\section{References}

[1] H. Sachse, Berichte 23 (1890) 1363.

[2] E. Juarist, Conformational Behavior of Six-Membered Rings, Methods in Stereochemical Analysis, VCH Publishers, New York, 1995.

[3] E.L. Eliel, N.L. Allinger, S.J. Angyal, Conformational Analysis, Wiley, New York, 1965.

[4] E.L. Eliel, S.H. Wilen, Stereochemistry of Organic Compounds, Wiley, New York, 1994.

[5] D.G. Morris, Stereochemistry, The Royal Society of Chemistry, Cambridge, UK, 2001.

[6] Available from $<$ http://chemicalland21.com/ $>$ in 2006/07/20.

[7] D. Cremer, J.S. Binkley, J.A. Pople, J. Am. Chem. Soc. 98 (1976) 6836.

[8] P.N. Kao, P.H. Turner, J. Am. Chem. Soc. 101 (1979) 4497.

[9] H.M. Badawi, J. Mol. Struct. (THEOCHEM.) 369 (1996) 75.

[10] B.K. Wiberg, J.D. Hammer, H. Castejon, W.F. Bailey, E.L. DeLeon, R.M. Jarret, J. Org. Chem. 64 (1999) 2085.

[11] B.K. Wiberg, J. Org. Chem. 64 (1999) 6387.

[12] E.A. Basso, P.R. Oliveira, J. Caetano, I.T.A. Schuquel, J. Braz. Chem. Soc. 12 (2001) 215.

[13] F. Cortés-Guzman, J. Hernández-Trujillo, G. Cuevas, J. Phys. Chem. A 107 (2003) 9253

[14] F. Taddei, E. Kleinpeter, J. Mol. Struct. (THEOCHEM.) 683 (2004) 29.

[15] M.P. Freitas, C.F. Tormena, R. Rittner, J. Mol. Struct. 570 (2001) 175.

[16] M.P. Freitas, C.F. Tormena, P.R. Oliveira, R. Rittner, J. Mol. Struct. (THEOCHEM.) 589-590 (2002) 147.

[17] M.P. Freitas, R. Rittner, C.F. Tormena, R.J. Abraham, Spectrochim. Acta A 61 (2005) 1771.

[18] F. Taddei, E. Kleinpeter, J. Mol. Struct. (THEOCHEM.) 718 (2005) 141.

[19] N.L. Allinger, N.A. Pamphilis, J. Org. Chem. 36 (1971) 3437.

[20] Y.L. Bennani, S. Hanessian, Chem. Rev. 97 (1997) 3161.

[21] G.D. Whitener, J.R. Hagadorn, J. Arnold, J. Chem. Soc. Dalton Trans. (1999) 1249.
[22] J.A. Gavin, N. Deng, M. Alcalá, T.E. Mallouk, Chem. Mater. 10 (1998) 1937

[23] J. Balsells, L. Mejorado, M. Phillips, F. Ortega, G. Aguirre, R. Somanathan, P.J. Walsh, Tetrahedron (Asymmetry) 9 (1998) 4135.

[24] A. Loussouarn, A. Ouadi, L. Morandeau, P. Remaud, R. Giles, J.-F. Gestin, J. Webb, Tetrahedron Lett. 44 (2003) 3539.

[25] J.E. Eilers, A. Liberles, J. Am. Chem. Soc. 97 (1975) 4183.

[26] D.A. Dixon, A. Komornicki, J. Phys. Chem. 94 (1990) 5630.

[27] M. Squillacote, R.S. Sheridan, O.L. Chapman, F.A.L. Anet, J. Am. Chem. Soc. 97 (1975) 3244.

[28] D.M. Ferguson, I.R. Gould, W.A. Glauser, I. Schroeder, P.A. Kollman, J. Comput. Chem. 13 (1992) 525.

[29] P. Hohenberg, W. Kohn, Phys. Rev. B 136 (1964) 864.

[30] W. Kohn, L.J. Sham, Phys. Rev. A 140 (1965) 1133.

[31] A.D. Becke, J. Chem. Phys. 98 (1993) 5648.

[32] A.D. Becke, Phys. Rev. A 38 (1988) 3098.

[33] C. Lee, W. Yang, R.G. Parr, Phys. Rev. B 37 (1988) 785.

[34] T.H. Dunning, J. Chem. Phys. 90 (1989) 1007.

[35] D.E. Woon, T.H. Dunning, J. Chem. Phys. 98 (1993) 1358.

[36] Gaussian 98, revision A.9, M.J. Frisch, G.W. Trucks, H.B. Schlegel, G.E. Scuseria, M.A. Robb, J.R. Cheeseman, V.G. Zakrzewski, J.A Montgomery, R.E. Stratmann, J.C. Burant, S. Dapprich, J.M. Millam, A.D. Daniels, K.N. Kudin, M.C. Strain, O. Farkas, J. Tomasi, V. Barone, M. Cossi, R. Cammi, B. Mennucci, C. Pomelli, C. Adamo, S. Clifford, J. Ochterski, G.A. Petersson, P.Y. Ayala, Q. Cui, K. Morokuma, D.K. Malick, A.D. Rabuck, K. Raghavachari, J.B. Foresman, J. Cioslowski, J.V. Ortiz, A.G. Baboul, B.B. Stefanov, G. Liu, A. Liashenko, P. Piskorz, I. Komaromi, R. Gomperts, R.L. Martin, D.J. Fox, T. Keith, M.A. Al-Laham, C.Y. Peng, A. Nanayakkara, M. Challacombe, P.M.W. Gill, B. Johnson, W. Chen, M.W. Wong, J.L. Andres, C. Gonzalez, M. Head-Gordon, E.S. Replogle, J.A. Pople, Gaussian, Inc., Pittsburgh, PA, 1998.

[37] J.W. Ochterski, Thermochemistry in Gaussian, available from $<$ http://www.gaussian.com/> in 2006/07/20.

[38] G.W. Buchanan, V.L. Webb, Tetrahedron Lett. 24 (1983) 4519.

[39] A. Bondi, J. Phys. Chem. 68 (1964) 441.

[40] F.-A. Kang, Y. Cheng-Lie, J. Am. Chem. Soc. 119 (1997) 8562.

[41] K.B. Wiberg, H. Castejon, W.F. Bailey, J. Ochterski, J. Org. Chem. 65 (2000) 1181.

[42] G.A. Jeffrey, An Introduction to Hydrogen Bonding, Oxford University Press, Oxford, 1997.

[43] T. Steiner, Angew. Chem. Int. Ed. 41 (2002) 48.

[44] N.N.L. Madhovi, A.M. Katz, H.L. Carrel, A. Nangia, G.R. Desiraju, Chem. Comm. (1997) 1953.

[45] T. Steiner, G.R. Desiraju, Chem. Comm. (1998) 891.

[46] M.B. Smith, J. March, March's Advanced Organic Chemistry, John Wiley \& Sons Inc., London, 2001. 